American Journal of Pharmaceutical Education 2019; 83 (4) Article 6722.

\title{
RESEARCH
}

\section{Student Pharmacists' Personal Finance Perceptions, Projected Indebtedness Upon Graduation, and Career Decision-making}

\author{
Nicholas E. Hagemeier, PharmD, PhD, ${ }^{a}$ Chad K. Gentry, PharmD, ${ }^{b}$ Debbie C. Byrd, PharmD, MBA, ${ }^{a}$ \\ L. Brian Cross, PharmD, ${ }^{a}$ Daniel Rose, PharmD, ${ }^{a}$ Nasar Ansari, PharmD, ${ }^{a}$ Pooja Subedi, MPH, ${ }^{a}$ \\ Tandy Branham, PharmD ${ }^{\mathrm{a}}$ \\ ${ }^{\text {a }}$ East Tennessee State University Gatton College of Pharmacy, Johnson City, Tennessee \\ ${ }^{\mathrm{b}}$ Lipscomb University College of Pharmacy, Nashville, Tennessee \\ Submitted August 14, 2017; accepted November 2, 2017; published May 2019.
}

Objective. To evaluate the extent to which Doctor of Pharmacy students' personal finance perceptions, projected student loan indebtedness, and demographic characteristics predict postgraduation career intentions.

Methods. Students at three pharmacy colleges completed a 31-item survey instrument that assessed personal finance perceptions, self-efficacy beliefs, anticipated student loan debt upon graduation, postgraduate intentions, anticipated practice setting upon graduation, and demographic characteristics. Logistic regression models were used to examine the extent to which personal finance perceptions, student loan indebtedness, and demographic characteristics predicted postgraduate intentions and anticipated practice setting.

Results. There were 763 usable responses obtained (response rate=90.3\%). Students reported an anticipated personal student loan debt at graduation of $\$ 162,747(\mathrm{SD}=\$ 87,093)$ and an estimated $7.4(\mathrm{SD}=5.8)$ years to pay off non-mortgage debt postgraduation. Fifty-three percent of students reported planning to practice in a community pharmacy setting postgraduation, and $54 \%$ indicated they intended to enter practice directly. Student loan indebtedness was not a significant predictor of whether students planned to pursue postgraduate training. There was a significant association between debt influence and pressure perceptions and students' plans to pursue postgraduate training $(\mathrm{aOR}=0.78 ; 95 \% \mathrm{CI}=0.65-0.94)$. The odds of indicating hospital (vs chain community) pharmacy as the anticipated setting decreased $36 \%$ with every one point increase in debt influence and pressure perceptions $(\mathrm{aOR}=0.64 ; 95 \% \mathrm{CI}=0.50-0.81)$.

Conclusion. Pharmacy students' perceived debt pressure and influence predicted their intention to enter practice directly (vs pursuing postgraduate training) and to select a career in chain community pharmacy (vs hospital pharmacy). Student loan indebtedness was not a significant predictor of postgraduate training intentions. These findings suggest that interventions that equip students to manage the pressure associated with large student loan debts should be explored.

Keywords: pharmacy student, debt, postgraduate training, career

\section{INTRODUCTION}

Indebtedness associated with earning the Doctor of Pharmacy (PharmD) degree has received increased attention in the pharmacy literature in the past decade.

Corresponding Author: Nicholas E. Hagemeier, Department of Pharmacy Practice, East Tennessee State University Gatton College of Pharmacy, Box 70657, Johnson City, TN 37614. Tel: 423-439-6239. Fax: 423-439-6784. E-mail: hagemeier@etsu.edu Note: Dr. Byrd was associate dean for professional affairs at the University of Tennessee during data collection. Drs. Rose, Ansari, and Branham were students enrolled in a Doctor of Pharmacy program while conducting this research.
From 2004 to 2014, the National Pharmacist Workforce Study noted a $154 \%$ increase $(\$ 42,600$ to $\$ 108,407)$ in average student loan indebtedness among pharmacists who had graduated within the previous five years and worked at least 30 hours per week. ${ }^{1}$ During the same period, the Institute for College Access and Success (TICAS) Project on Student Debt found that for students graduating from a four-year college, the average student loan debt increased by $56 \%$ from $\$ 18,550$ in 2004 to $\$ 28,950$ in $2014 .^{2}$ During the same timeframe, the United States Bureau of Labor Statistics reported a $48 \%$ increase in the mean annual wage for all pharmacists in the United 


\section{American Journal of Pharmaceutical Education 2019; 83 (4) Article 6722.}

States $(\$ 80,300$ to $\$ 118,470) .{ }^{3-5}$ Thus, while pharmacists begin their careers with a higher than average amount of student loan debt, they earn relatively high wages.

Human capital theory posits an educational investment as being similar to a capital investment. An educational investment is composed of both monetary investment (tuition) and opportunity cost (time spent in school). As students weigh the cost of educational investment against the benefits of a given job, they will, in theory, make decisions that maximize long-term gain. ${ }^{6}$ Considering pharmacy school and postgraduate training specifically, students must weigh the benefits and costs of pursuing postgraduate training vs entering practice directly. Previous research has found that net career earnings associated with a PharmD degree are favorable, but the return on investment of postgraduate training after completing a PharmD degree is negative or low at best. ${ }^{7-9}$ Yusuf and colleagues posited that pharmacists would be more likely to choose a job that would maximize earnings, thereby reaping larger returns on their educational investment. ${ }^{10}$ They found that pharmacists with low indebtedness were more likely to enter independent practice as compared to chain pharmacy practice, but did not find other significant associations between student loan debt and career decision-making. ${ }^{10}$ Park and colleagues examined the attitudes of pharmacy students toward debt and found that students of non-white ethnicity and female gender were more likely to have negative attitudes toward debt compared with those of white ethnicity or male gender. ${ }^{11}$ Additionally, students' knowledge of the amount of debt they have accrued also impacts their attitudes toward debt. In a 2003-2004 study at one college of pharmacy, McCollum and Hansen found that level of indebtedness (less than $\$ 40,000$ vs $\$ 40,000$ or more) was not associated with the decision to pursue or not pursue residency training. ${ }^{12}$ More recently, research by Chisholm-Burns and colleagues found that fear of debt among students at one college was associated with increased indebtedness and perceived stress. ${ }^{13}$ Also, students' attitudes toward debt did not differ based on their postgraduation plans. ${ }^{13}$

While there are limited data available regarding pharmacy students' personal finance competency, Chui suggested that many pharmacy students are ill-equipped to handle personal finance decisions. ${ }^{14}$ Prior to participation in a personal finance class, students scored an average of $60.0 \%$ on a modified version of the 2006 Jump\$tart Financial Literacy Survey. This improved to $89.9 \%$ on a post-class assessment. ${ }^{14}$ For comparison, the 2008 Jump\$tart Financial Literacy Survey found that college freshmen averaged 59\%, while seniors averaged $65 \%$. $^{15}$
Although research has been published examining the return on investment in pharmacy education, no recent studies have evaluated pharmacy students' perceptions of debt prior to graduation and the impact of debt on career decision-making. ${ }^{16-18}$ The objective of this study was to examine the extent to which personal finance perceptions, projected student loan indebtedness, and demographic characteristics predict PharmD students' career intentions after graduation.

\section{METHODS}

A 31-item survey instrument was developed to assess student pharmacists' personal finance perceptions, personal finance behaviors, self-efficacy beliefs, anticipated student loan debt upon graduation, postgraduate intentions, and anticipated practice setting upon graduation. Students responded to perception and self-efficacy items using a five-point Likert response scale on which $1=$ strongly disagree and $5=$ strongly agree. Behaviors were evaluated with multiple-choice and true/false items. To evaluate postgraduate training intentions, students were asked, "Which of the following postgraduate paths best describes your current intentions after pharmacy school?" Responses included direct entry in to practice, fellowship training, graduate school, residency training, and other. Students' anticipated primary practice setting was assessed by asking students to choose one setting from a list of nine common settings (including "other").

Students from three colleges of pharmacy were recruited to participate in the study and represented one public institution (two student cohorts), one private institution (three cohorts), and one private college within a public institution (four cohorts). Students were recruited during the 2013-2014, 2014-2015 and 2015-2016 academic years and were either second- or third-professional year pharmacy students. Survey administration (paperbased vs online survey software) was college dependent. Recruitment was championed by one faculty member at each college. All faculty champions taught or facilitated a personal finance course based on the program "Foundations in Personal Finance" at their respective institutions. ${ }^{19}$ Whereas the delivery methods differed across the institutions (eg, elective course, required stand-alone course, content embedded into required course), questionnaires were completed prior to students taking any personal finance course while enrolled in the professional program. Prior to conducting the study, all sites received approval from their respective institutional review boards.

Data analysis was conducted using SPSS Statistics, version 22 (IBM Corp, Armonk, NY), and SAS, version 9.4 (SAS, Cary, NC). Exploratory factor analysis was conducted to explore the underlying factor structure for 


\section{American Journal of Pharmaceutical Education 2019; 83 (4) Article 6722.}

15 items developed to assess students' personal finance perceptions. An Eigenvalue cutoff of $>1$ was used to preliminarily identify the number of factors to retain. A principal axis factoring extraction method and promax rotation were employed. An item was allowed to represent a factor if it had a loading greater than 0.4 on that factor and no loading on another factor within 0.2 of the one on which it loaded most. Factor analysis resulted in the 15 items loading on three factors: personal finance self-efficacy beliefs, debt influence and pressure, and risk mitigation and retirement. Cronbach alphas for the three constructs ranged from 0.75 to 0.88 . Weighted construct scores were calculated for each student and used in subsequent analyses.

Age, number of dependents, anticipated student loan debt at graduation (in 10,000s), and personal finance perception constructs were treated as continuous variables. Marital status was dichotomized to students in a relationship (married, engaged) and not in a relationship (single, divorced/separated, widowed). Univariate and multivariable logistic regression models were used to examine the extent to which personal finance perceptions, student loan

Table 1. Demographics and Personal Finance Characteristics of Study Participants $(\mathrm{N}=763)^{\mathrm{a}}$

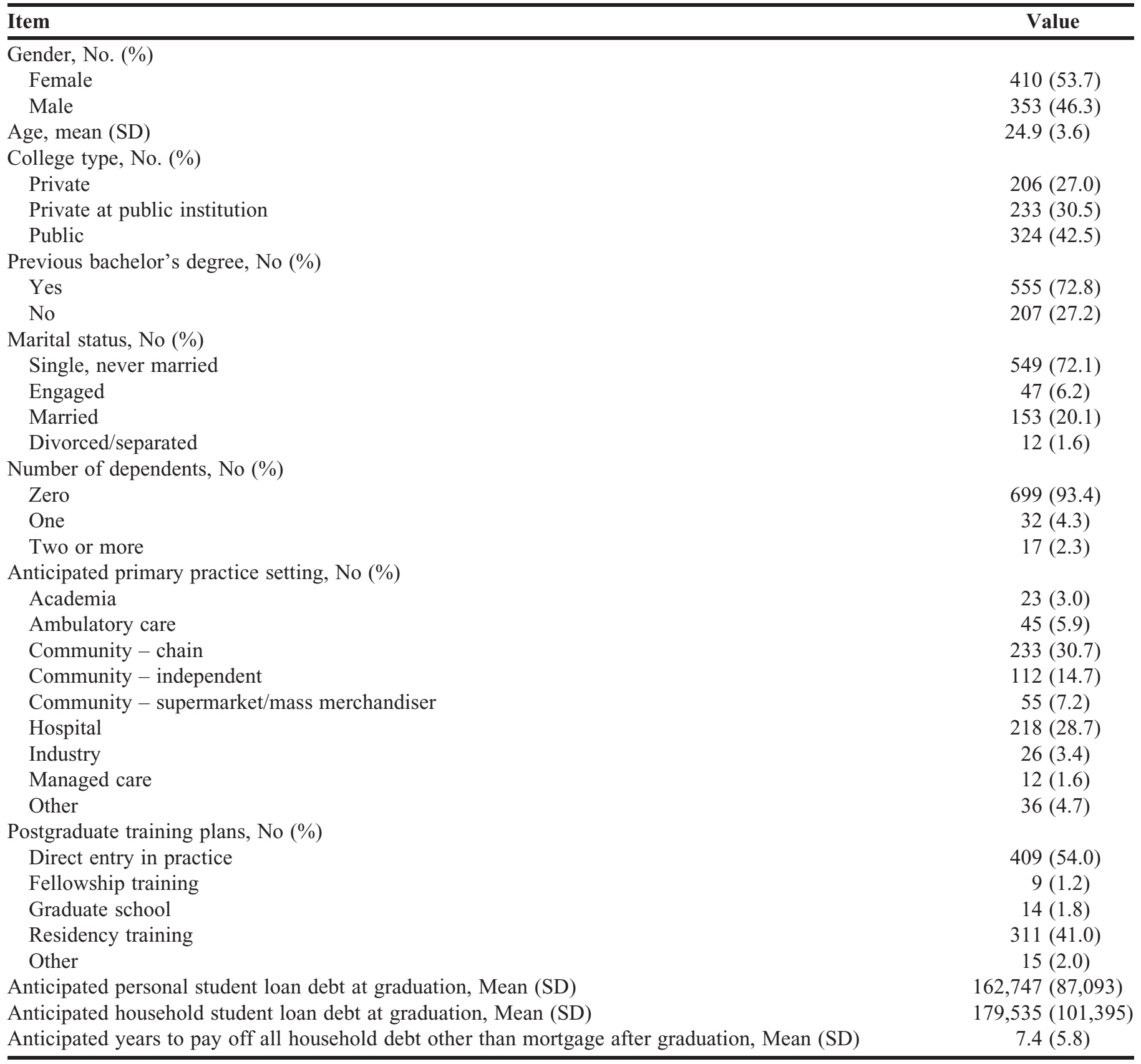

a The number of respondents per item varies $(\mathrm{N}<763)$ with the number of respondents who provided a response 


\section{American Journal of Pharmaceutical Education 2019; 83 (4) Article 6722.}

indebtedness, and demographic characteristics predicted postgraduate intentions (entering vs not entering direct practice). Similarly, multinomial logistic regression models were used to examine the extent to which personal finance perceptions, student loan indebtedness, and demographic characteristics predicted anticipated practice setting (independent, chain, supermarket/mass merchandiser, hospital, and other).

\section{RESULTS}

A total of 763 usable responses were obtained across the three colleges (response rate of $90.3 \%$ ). Table 1 presents students' demographic, career, and personal finance characteristics. Overall, $53 \%$ of students planned to practice in a community pharmacy setting after graduation, while $54 \%$ of students planned to enter practice directly. Students reported a mean anticipated personal student loan debt at graduation of $\$ 162,747$ and an estimated 7.4 years to pay off all non-mortgage household debt after graduation.

Responses to Likert-scale items assessing personal finance perceptions are presented in Table 2. Unweighted mean scores across personal finance constructs were 3.1 $(\mathrm{SD}=0.9)$ for risk mitigation and retirement perceptions, $3.7(\mathrm{SD}=0.9)$ for debt influence and pressure, and 3.7 $(\mathrm{SD}=0.8)$ for personal finance self-efficacy beliefs. Higher risk mitigation and retirement and self-efficacy perceptions indicate positive perceptions of financial pre- paredness whereas higher debt influence and pressure scores indicate an increased sense of pressure.

The univariate and multivariable associations between student demographic characteristics, personal finance characteristics and perceptions, and postgraduate training plans are presented in Table 3. Anticipated student loan indebtedness was not a significant predictor of planning to pursue postgraduate training. In univariate analyses, a one-point increase in debt influence and pressure perceptions was associated with a $23 \%$ decrease in intention to pursue postgraduate training $(\mathrm{OR}=0.77 ; 95 \%$ CI $=0.65-0.91$, $p=.002$ ). Multivariable analysis revealed a similar significant association between debt influence and pressure perceptions (adjusted odds ratio $(\mathrm{aOR})=0.78 ; 95 \%$ $\mathrm{CI}=0.65-0.94, p=.009)$. No other significant associations were noted in relation to pursuing postgraduate training.

The results of multinomial logistic regression analysis for choice of primary practice setting postgraduation are presented in Table 4. As compared to students who selected chain community as their anticipated practice setting, students who selected independent pharmacy practice were less likely to be in a relationship ( $\mathrm{OR}=0.54 ; 95 \%$ $\mathrm{CI}=0.31-0.94, p=.028)$ and less likely to have a bachelor's degree $(\mathrm{OR}=0.51 ; 95 \% \mathrm{CI}=0.30-0.86, p=.012)$. The odds of entering supermarket/mass merchandise community pharmacy (vs. chain community pharmacy) decreased $4 \%$ for every $\$ 10,000$ in student loan debt a student had $(\mathrm{OR}=0.96 ; 95 \% \mathrm{CI}=0.92-0.99, p=.045)$. Similarly, the

Table 2. Pharmacy Student Personal Finance Constructs and Perceptions. $(\mathrm{N}=763)$

\begin{tabular}{|c|c|c|c|}
\hline Item/Construct & $\begin{array}{c}\text { Median } \\
\text { (IQR) }\end{array}$ & Mean (SD) & $\begin{array}{c}\text { Cronbach's } \\
\text { Alpha }\end{array}$ \\
\hline $\begin{array}{l}\text { Personal Finance Self-Efficacy } \\
\text { I'm confident in my ability to manage my personal finances } \\
\text { I'm confident in my ability to get out of debt after I graduate } \\
\text { I have a plan to get out of debt once I graduate } \\
\text { I am confident in my ability to develop a personal budget } \\
\text { I am confident in my ability to stick to a budget once it is developed } \\
\text { I am confident in my ability to save appropriately for my retirement } \\
\text { I am confident in my ability to save money for major purchases over } \\
\$ 10,000\end{array}$ & $\begin{array}{l}4(3-5) \\
4(4-5) \\
4(3-4) \\
4(3-5) \\
4(3-4) \\
4(3-4) \\
4(3-4)\end{array}$ & $\begin{array}{l}3.81(0.99) \\
4.05(0.98) \\
3.58(1.12) \\
3.79(1.00) \\
3.62(1.06) \\
3.63(1.06) \\
3.62(1.10)\end{array}$ & 0.88 \\
\hline $\begin{array}{l}\text { Debt Influence and Pressure } \\
\text { I'm concerned about my anticipated debt load after I graduate } \\
\text { I feel pressured to get out of debt after I graduate from pharmacy school } \\
\text { My debt load factors in to my career plans after I graduate } \\
\text { My debt load influences my decision to pursue postgraduate training }\end{array}$ & $\begin{array}{l}4(3-5) \\
4(3-5) \\
4(3-5) \\
3(2-4)\end{array}$ & $\begin{array}{l}3.96(1.18) \\
4.02(1.11) \\
3.62(1.19) \\
3.23(1.26)\end{array}$ & 0.75 \\
\hline $\begin{array}{l}\text { Risk Mitigation and Retirement } \\
\text { My retirement goals influence my anticipated career path after graduation } \\
\text { I have a plan to fund my retirement after I graduate } \\
\text { I have a good understanding of the role of insurance in protecting my assets } \\
\text { I am confident in my ability to choose appropriate investment options }\end{array}$ & $\begin{array}{l}3(3-4) \\
3(2-4) \\
3(2-4) \\
3(2-4)\end{array}$ & $\begin{array}{l}3.37(1.13) \\
3.22(1.22) \\
3.16(1.26) \\
2.81(1.25)\end{array}$ & 0.76 \\
\hline
\end{tabular}

$\mathrm{IQR}=$ interquartile range; $\mathrm{SD}=$ standard deviation 


\section{American Journal of Pharmaceutical Education 2019; 83 (4) Article 6722.}

Table 3. Associations Between Pharmacy Student Characteristics and Perceptions and Pursuance of Postgraduate Training $(\mathrm{N}=763)$

\begin{tabular}{lcccc}
\hline Variable & $\begin{array}{c}\text { Unadjusted OR } \\
(\mathbf{9 5 \%} \mathbf{C I})\end{array}$ & $\boldsymbol{p}$ Value & $\begin{array}{c}\text { Adjusted } \mathbf{O R}^{\mathbf{a}} \\
\mathbf{( 9 5 \%} \mathbf{C I})\end{array}$ & $\boldsymbol{p}$ Value \\
\hline Age & $1.00(0.96-1.04)$ & .924 & $1.01(0.96-1.06)$ & .677 \\
Female vs. male & $1.06(0.80-1.41)$ & .686 & $1.05(0.77-1.43)$ & .768 \\
In a relationship vs. not & $0.83(0.60-1.15)$ & .264 & $0.83(0.57-1.21)$ & .342 \\
Number of dependents & $1.06(0.75-1.50)$ & .733 & $1.31(0.84-2.04)$ & .240 \\
Bachelor's degree vs. not & $1.24(0.90-1.71)$ & .198 & $1.09(0.76-1.57)$ & .626 \\
$\begin{array}{l}\text { Anticipated student loan debt at } \\
\quad \text { graduation (in 10,000s) }\end{array}$ & $1.00(0.98-1.01)$ & .638 & $1.00(0.98-1.02)$ & .837 \\
Personal finance self-efficacy & & & & \\
Debt pressure perceptions & $0.92(0.79-1.08)$ & .314 & $1.10(0.84-1.43)$ & .500 \\
Risk and retirement perceptions & $0.77(0.65-0.91)$ & .002 & $0.78(0.65-0.94)$ & .009 \\
\hline
\end{tabular}

$\mathrm{OR}=$ odds ratio; $\mathrm{CI}=$ confidence interval

${ }^{\text {a }}$ Adjusted for other variables included in the model

odds of indicating hospital pharmacy (vs chain community pharmacy) as the anticipated work setting after graduation decreased $36 \%$ with every one-point increase in debt influence and pressure perceptions $(\mathrm{OR}=0.64 ; 95 \%$ $\mathrm{CI}=0.50-0.81, p<.001)$.

\section{DISCUSSION}

Given recent emphasis on indebtedness associated with obtaining a PharmD degree, we sought to describe student pharmacists' personal finance perceptions and examine the extent to which personal finance perceptions, student loan indebtedness, and demographic characteristics predict students' post-PharmD career intentions. To our knowledge, this is the first study to examine personal finance-related correlates of postPharmD career planning across multiple institutions. While Yusuf et al found that lower student loan indebtedness was associated with choosing to work at an independent rather than a chain pharmacy, this study found that less indebtedness was associated with choosing the supermarket/mass merchandise setting rather than the chain setting. ${ }^{10}$ Across the three colleges studied, only one significant association (supermarket/mass merchandise vs chain community) was noted between students' anticipated student loan indebtedness at graduation and either choice of practice setting or the decision to pursue postgraduate training. Interestingly, a perception of debt influence and pressure associated with having student loan debt, regardless of the actual level of student loan debt anticipated at graduation, was significantly positively correlated with intention to enter practice directly (as compared to pursuing postgraduate training) and intention to work in the chain community pharmacy setting (as compared to hospital pharmacy). These findings are likely related given the large number of students who indicated residency as their postgraduate training path and the extent to which PGY-1 residencies take place in hospital settings.

While anticipated student loan debt value was not a statistically significant predictor of students pursuing postgraduate training, perceived debt pressure and influence was a statistically significant predictor. The correlation between debt pressure and anticipated student loan debt was $\mathrm{r}=0.340, p<.001$. The items that comprised the debt pressure factor focused on concern with debt and pressure associated with debt, as well as the influence of debt on career plans. Whereas Cain et al speak to financial pressures at the state level as a factor that influences student indebtedness, this study indicates that perceived debt pressure influences career decision-making at the student level. ${ }^{17}$ This is similar to the finding by Chisholm-Burns and colleagues that stress and debt level are positively correlated. ${ }^{13}$ This finding could potentially serve as an intervention point for colleges if educating students about and equipping students to manage student loan debt postgraduation mitigates that pressure. Based on this study, an intervention that focuses on equipping students to manage the pressure associated with accruing student loan debt, in addition to managing debt load, may have more influence on career decision-making than interventions that decrease actual student loan debt. Also, the debt pressure and influence perceptions could be related to other characteristics or situations (eg, family pressures, religious beliefs, stress) that were not addressed in the survey instrument. The work by Chisholm-Burns and colleagues supports this. ${ }^{13}$ Schools and colleges may be able to assist students with individual variables that influence debt pressure with targeted interventions. McCollum and colleagues noted that salary level, a perception of high debt, and family obligations were factors that influenced 
American Journal of Pharmaceutical Education 2019; 83 (4) Article 6722.

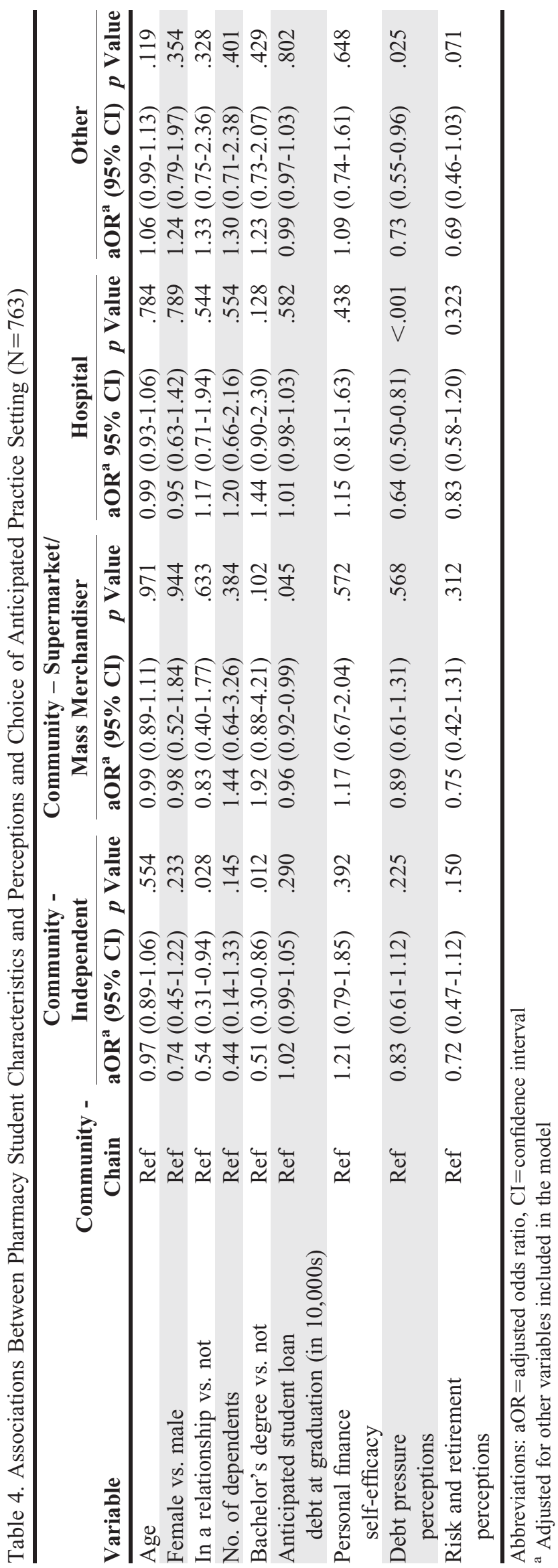




\section{American Journal of Pharmaceutical Education 2019; 83 (4) Article 6722.}

students' decisions not to pursue residency training. ${ }^{12}$ There was no evidence found in our study of family obligations, such as the number of dependents or relationship status, playing a role in whether students pursued postgraduate training. Two additional characteristics that warrant further study are the students' parents' income and parents' net worth as students' perceptions of debt pressure may be related to the environments in which they were raised.

There were several limitations to this study that warrant consideration. Given the cross-sectional nature of the study design, we could not examine the extent to which anticipated post-PharmD plans matched the actual career/ training paths pursued post-PharmD. Moreover, the extent to which students are able to accurately predict student loan debt upon graduation is unknown. Additionally, whereas the exploratory factor analysis of the personal finance perception items resulted in three well-defined factors with good internal consistency, additional validity testing is warranted. Finally, while multiple cohorts of students from three institutions were included in the study, caution should be used when generalizing our findings to student pharmacists at other institutions.

\section{CONCLUSION}

While students' anticipated loan debt at graduation did not have significant influence on the decision to pursue postgraduate training, this study demonstrated that students' perceptions of debt predicted direct entry into practice. Increases in students' debt pressure perceptions were associated with increased selection of chain community pharmacy as a practice setting as compared to hospital pharmacy. Additional demographic characteristics that could be expected to influence career decisions (eg, age, relationship status, dependents, time already spent in school) did not routinely do so. Future studies should investigate the relationship between students' personal finance characteristics and actual post-PharmD career decisions.

\section{REFERENCES}

1. Midwest Pharmacy Workforce Research Consortium. Final report of the 2014 national sample survey of the pharmacist workforce to determine contemporary demographic practice characteristics and quality of work-life. Minneapolis, MN; 2015.

2. The Institute for College Access \& Success. Student Debt and the Class of 2014. Washington, DC; 2015.
3. Bureau of Labor Statistics USDoL. Occupational Employment Statistics: May 2004. http://www.bls.gov/oes/special.requests/ oesm04in4.zip.

4. Bureau of Labor Statistics USDoL. Occupational Employment Statistics: 2009. http://www.bls.gov/oes/special.requests/ oesm09in4.zip.

5. Bureau of Labor Statistics USDoL. Occupational Employment Statistics: May 2014. http://www.bls.gov/oes/special.requests/ oesm14nat.zip.

6. Sweetland SR. Human capital theory: Foundations of a field of inquiry. Review of Educational Research.

1996;66(3):341-359.

7. Hagemeier NE, Murawski MM. Economic analysis of earning a $\mathrm{PhD}$ after completion of a PharmD degree. Am J Pharm Educ. 2011;75(1):Article 15.

8. Chisholm-Burns MA, Gatwood J, Spivey CA. Economic Analysis of Obtaining a PharmD Degree and Career as a Pharmacist. Am J Pharm Educ. 2015;79(8):Article 117.

9. Chisholm-Burns MA, Gatwood J, Spivey CA, Dickey SE. BreakEven Income Analysis of Pharmacy Graduates Compared to High School and College Graduates. Am J Pharm Educ. 2016;80(3): Article 44.

10. Yusuf AA, Schommer JC, Mott DA, Doucette WR, Gaither CA, Kreling DH. Association between student loan debt on graduation, demographic characteristics and initial choice of practice setting of pharmacists. Innovations in Pharmacy. 2011;2(3): Article 51.

11. Park T, Yusuf AA, Hadsall RS. Pharmacy Students' Attitudes Toward Debt. Am J Pharm Educ. 2015;79(4):Article 52. 12. McCollum M, Hansen LB. Characteristics of Doctor of Pharmacy graduates entering and not entering residency training upon graduation. Am J Pharm Educ. 2005;69(3): Article 42.

13. Chisholm-Burns MA, Spivey CA, Jaeger MC, Williams J. Associations between Pharmacy Students' Attitudes Toward Debt, Perceived Stress, and Federal Student Loans Borrowed. Am J Pharm Educ. 2017; Early online August 3.

14. Chui MA. An Elective Course in Personal Finance for Health Care Professionals. Am J Pharm Educ. 2009;73(1):Article 6.

15. Financial Literacy Declining Among High School Seniors [press release]. Washington, DC; 2008.

16. Cain J, Campbell T, Congdon HB, et al. Pharmacy student debt and return on investment of a pharmacy education. Am J Pharm Educ. 2014;78(1):Article 5.

17. Cain J, Campbell T, Congdon HB, et al. Complex issues affecting student pharmacist debt. Am J Pharm Educ.

2014;78(7):Article 131.

18. Sweet BV, Kelley KA, Janke KK, et al. Career Placement of Doctor of Pharmacy Graduates at Eight U.S. Midwestern Schools. Am J Pharm Educ. 2015;79(6):Article 88.

19. Ramsey D. Foundations in Personal Finance College Edition. Brentwood, TN: Lampo Licensing; 2011. 